\title{
Time-Driven Activity-Based Costing for Inter-Library Services: A Case Study in a University
}

\author{
by Eli Pernot, Filip Roodhooft, and Alexandra Van den Abbeele
}

Available online 12 July 2007

\begin{abstract}
Although the true costs of inter-library loans
(ILL) are unknown, universities increasingly rely on them to provide better library services at lower costs. Through a case study, we show how to perform a time-driven activity-based costing analysis of ILL and provide evidence of the benefits of such an analysis.
\end{abstract}

Eli Pernot is aspirant of the Fund for Scientific Research, Flanders. Katholieke Universiteit Leuven, Naamsestraat 69, 3000 Leuven, Belgium $<$ eli.pernot@econ.kuleuven.be>;

Filip Roodhooft, Katholieke Universiteit Leuven, Naamsestraat 69, 3000 Leuven, Belgium Vlerick Leuven Gent Management School, Leuven Campus Vlamingenstraat 83 3000 Leuven, Belgium

$<$ filip.roodhooft@econ.kuleuven.be>; Alexandra Van den Abbeele, Katholieke Universiteit Leuven, Naamsestraat 69, 3000 Leuven, Belgium <alexandra.vandenabbeele@econ.kuleuven.be>.

\section{INTRODUCTION}

Ever diminishing university funding by the government ${ }^{1-4}$ urges university library management to provide better library services at a continuously lower cost. ${ }^{2}$ To cope with these cost pressures, library management needs to improve its understanding of the relevant cost drivers.

To date, most studies on university library costs have relied on traditional activity-based costing (ABC) systems. ${ }^{2,3,5}$ Although these studies found $\mathrm{ABC}$ both providing library management with a more detailed cost analysis of activities and services, and assisting management in understanding what actually causes certain costs, ${ }^{2,3} \mathrm{ABC}$ also appeared to cause two significant problems. First, setting up an ABC system can be very costly, especially if the current accounting system does not support the collection of ABC information. Second, the system needs to be regularly updated, which further increases its cost. ${ }^{3}$ These limitations motivated Kaplan and Anderson ${ }^{6}$ to develop timedriven activity-based costing (TDABC), a revised version of $\mathrm{ABC}$, solving these problems, without losing the benefits. The most important characteristic of this technique is its simplicity, as only two kinds of parameters need to be estimated: the number of time units (e.g. minutes) consumed by the activities related to the cost objects and the cost per time unit. Hence, TDABC systems cannot only be implemented quicker (and thus cheaper), but also updated easier, than traditional ABC systems. ${ }^{6}$

Since services constitute the ideal setting to implement a TDABC system in order to improve the service's cost management, we performed a case study at the Arenberg library of the Catholic University of Leuven (KULeuven). Although we argue that TDABC could improve the cost management of all library services, as identified by Ellis-Newman and Robinson, ${ }^{2}$ EllisNewman, ${ }^{3}$ and Goddard and Ooi, ${ }^{5}$ we only concentrated on the inter-library loan (ILL) service, for several reasons. First, ILL is directly linked to the increasing cost pressures on university libraries. Indeed, Nitecki and Renfro ${ }^{7}$ confirm that library management relies more and more on ILL, in order to provide good library services in times of decreasing library buying power. When books or journals are not available in the library of choice, readers can request them from other libraries via the twodirectional ILL system. Second, an accurate cost calculation is important for ILL services. On the one hand, the processing costs for an inter-library loan are higher than for an internal loan, because inter-library loans require higher-level staff and are 
more time consuming to process. ${ }^{3,8}$ On the other hand, also the costs of different ILL requests vary significantly, with a huge difference between straightforward requests and the most difficult ones. Hence, allocating the same amount of costs to these different types of requests would be inaccurate. ${ }^{3}$ Third, contrary to overall library costs, specific ILL costs have been extensively studied in the past, frequently as one of the four general agreed ILL evaluation criteria: fill rate, turnaround time, user satisfaction and cost. ${ }^{9}$ In the following paragraphs, we summarize the findings of some relevant studies. For a more extensive overview of ILL cost studies, we refer to Stein. ${ }^{9}$

In 1992 the Association of Research Libraries (ARL), conducted the first major ILL cost study in North America and found that research libraries spent on average $* \$ 18.62$ to borrow (ranging from $\$ 9.84$ to $\$ 30.27$ ) and $\$ 10.93$ (ranging from $\$ 6.92$ to $\$ 17.49$ ) to lend via ILL. ${ }^{10}$ The follow-up study ${ }^{11}$ by ARL expanded the research to all four ILL performance measures and increased the library sample from seventy-six to ninety-seven research libraries. ILL costs appeared to have declined slightly to $\$ 18.35$ for borrowing and $\$ 9.48$ for lending. Additionally, twenty-two college libraries were questioned, that showed significantly lower ILL borrowing costs of $\$ 12.08$ and lending costs of $\$ 7.25$. $^{11}$ The ARL methodology was subsequently adapted for use in Australia and the Nordic countries (Denmark, Finland, Iceland, Norway and Sweden). In Australia, the average borrowing unit cost was AU\$32.09, ${ }^{12}$ while research in the Nordic revealed an average borrowing unit cost of $€ 12.56$ and average lending cost of $€ 7.24$. $^{13}$

The second ARL performance measurement study ${ }^{14,15}$ of seventy-two North American research, college, and governmental libraries also measured patron-initiated (or unmediated) ILL criteria and found lower unit costs than for mediated ILL services. Borrowing unit costs for user-initiated ILL ranged from $\$ 2.39$ to $\$ 14.7$, compared to $\$ 17.50$ for mediated ILL. Similar results were found for lending, with a lending unit cost for user-initiated ILL ranging from \$3.27 to \$12.06 and \$9.27 for mediated ILL. ${ }^{14,15}$ Yet, the most famous consortium regarding patron-initiated ILL is undoubtedly OhioLINK, a consortium of Ohio-based college and university libraries, which created an alternative for traditional ILL. By utilizing user-initiated requests, a single automated system for fifty-two library collections, a commercial delivery service, and a staffing context that requires little more than low-cost student labor, OhioLINK has achieved average ILL unit costs of not more than one dollar. Therefore, OhioLINK members made ILL affordable on a mass volume basis and do not even call it ILL any longer, but simple circulation. ${ }^{16,17}$

A similar patron-initiated borrowing service project was implemented by seven private East Coast institutions and called "Borrow Direct". Compared to traditional ILL costs, Borrow Direct achieves significantly lower per-transaction costs, namely $\$ 5.33$ for borrowing and $\$ 6.48$ for lending. ${ }^{7}$ Nevertheless, these interlending costs remain higher than OhioLINK costs, primarily because Borrow Direct members do not share a common automated system and must operate across state lines. ${ }^{17}$ The same cost comparison can be made for the Jefferson County Public Library (JCPL), member of the Prospector INN-Reach consortium in Colorado, although the ILL per-transaction costs of Prospector appeared much closer to the OhioLINK costs: $\$ 1.17$ for lending and $\$ 1.56$ for borrowing. ${ }^{18}$ Another very recent ILL cost investigation was conducted at the US National Institute of Standards and
Technology (NIST) Library and revealed a significant increase in the total average cost per request, from \$29.91 in 2003 to $\$ 41.20$ in $2004 .^{19}$

We would like to contribute to this ILL cost study literature by providing a whole new approach, based on time-driven activitybased costing (TDABC), for calculating ILL costs. Contrary to traditional ILL cost studies such as the ARL studies, TDABC does not follow Lor's "macro-approach" of dividing yearly aggregated costs by total number of requests filled, but the "micro approach", involving cost data collection and calculation for the various steps in ILL processing. This way, the TDABC approach results in disaggregated costs for all ILL service activities, instead of aggregated dollar figures like $\$ x$ for borrowing and $\$ x$ for lending. As the KULeuven library manager confirmed that "ILL is extremely time consuming, difficult to define in terms of subactivities, significantly different across the requests and costly", the in-depth TDABC analysis really answers a practitioner's request in order to reveal the true cost of ILL and clearly show what activities cause the costs.

The remainder of this paper is organized as follows. First, we present the inter-library TDABC case. Second, we discuss the management implications resulting from our analysis. Third, we end the paper with a brief conclusion.

\section{Time-Driven Activity-Based Costing for INTER-LIBRARY LOANS}

In this part of the paper, we thoroughly explain the inter-library TDABC analysis. To that end, we first briefly describe ILL at the KULeuven Arenberg library. Then, we present a thorough activity analysis and derive time equations for each request activity. Third, we provide an overview of all related ILL costs and identify the different costs per minute. Based on these time equations and costs per minute, we finally calculate the cost of different outgoing and incoming requests.

The activity data for this study were gathered through direct observation and multiple interviews with both the library manager and the ILL responsible (cf. Goddard and Ooi ${ }^{5}$ ). Cost data were obtained from the library accountant and other information was found by means of archival research, which included inter alia the annual report. All observations were made during 2006 and all financial data (like wages and overhead costs) are from 2005.

\section{Inter-Library Loans (ILL) at the KULeuven Arenberg Library}

The KULeuven Arenberg library's mission is “to develop a well-balanced collection for education and research, with extended opening hours for students, an electronic library that can be consulted at individual workplaces and the facilities for guided self-education" (Annual Report, 2005). The recent trends to automate standard processes, like lending and receiving books, and to digitalize the library are aimed at attaining this goal at the lowest possible cost. Furthermore, the library is a member of the LIBIS-network, which manages the library systems of the entire KULeuven and LIBIS-Net. LIBISNet's mission is to support participating libraries in their library management and the services they provide, such as ILL. Like any other ILL system, LIBIS-Net. supports on the one hand that the KULeuven library borrows books and requests journal articles that are not present in its collection, the socalled outgoing requests, and on the other hand that the library lends items to other libraries, the so-called incoming requests. 
Although ILL basically only refers to "loans", we will use the term in the remainder of this paper to refer to both books loans and article deliveries.

Fig. 1 depicts the relations between the three parties involved in an outgoing request, which generally consists out of three flows.

Only when a book is not returned within the allowed borrowing period, the library sends a reminder for return, creating a fourth flow (4). Obviously, when the request concerns a journal article, the ILL process stops after flows 1 and 2, because a PDF file or a hard copy must not be returned. For most Belgian libraries, payment for ILL is handled by the clearinghouse system of Impala, comparing earnings and dues on a 1 to 1 basis. While libraries with a negative balance receive an invoice from Impala, those libraries with a positive balance may send the clearing-house an invoice. When payment is not handled by Impala, the KULeuven library either receives an invoice from the other library or settles the payment by means of an IFLA (International Federation of Library Associations) voucher, the latter being utilized more and more frequently for international ILL services. Obviously, the KULeuven library charges the reader for the ILL costs. All financial transactions follow flows (2) and (3) in Fig. 1, but do not have to coincide with the physical flow of the book or article.

From the perspective of the KULeuven library, incoming requests involve only two parties and consist of three flows when the ILL concerns a book loan, represented in Fig. 2.

\section{Activity Analysis and Time Equations}

To construct appropriate time equations, we performed a thorough activity analysis of ILL at the Arenberg library. We identified four common ILL activities (process, deliver, close and invoice), each implying several subactivities, which differ for outgoing and incoming requests. For each of these subactivities, the ILL responsible at the KULeuven library

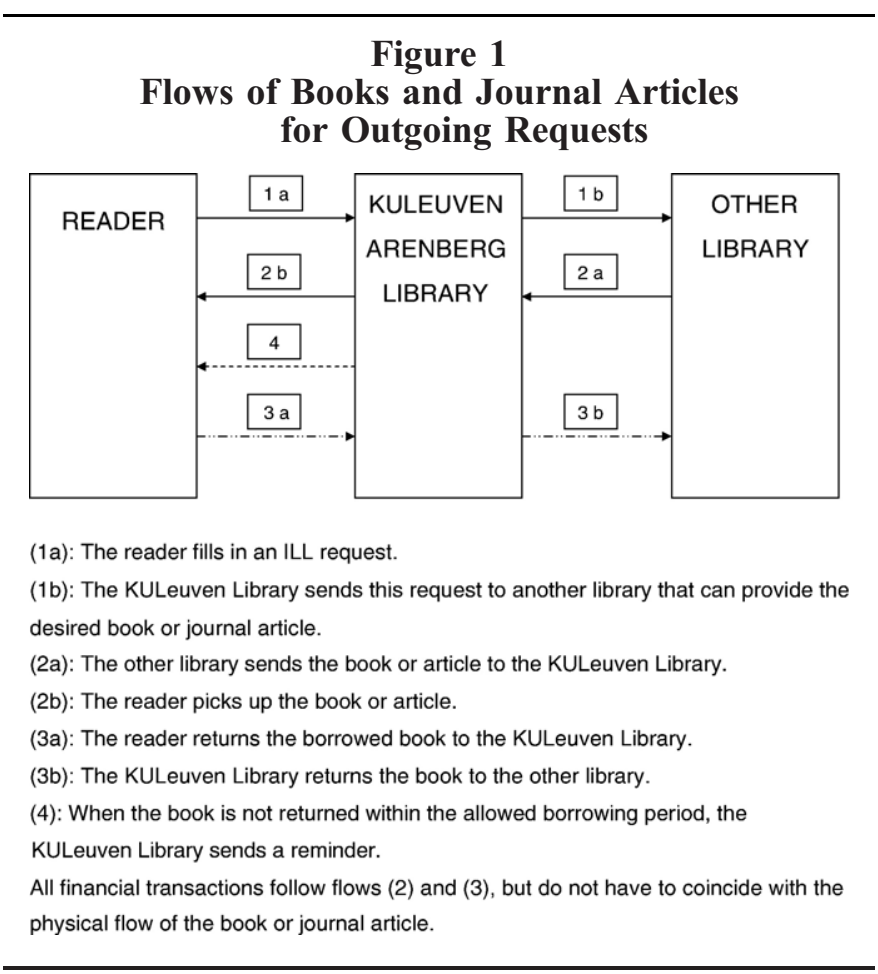

\section{Figure 2 \\ Flows of Books and Journal Articles for Incoming Requests}

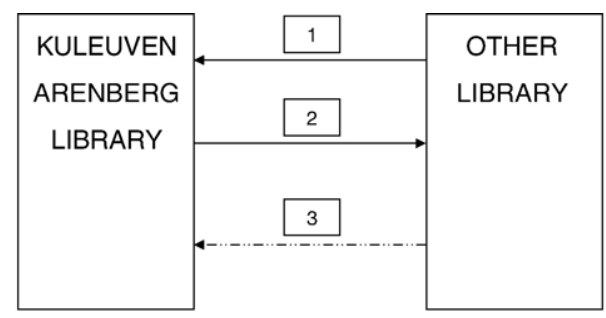

(1): Another library sends an ILL request to the KULeuven Library.

(2): The KULeuven Library sends the book or article to the other library.

(3): The other library returns the book to the KULeuven Library.

All financial transactions follow flows (2) and (3), but do not have to coincide with the physical flow of the book or journal article. provided an estimation of the time needed to perform this subactivity once. Based on these estimations, we derived eight time equations, one for every main activity of an outgoing and incoming request, which can be found in Table 1 .

The interpretation of these time equations is similar for all equations. The total time needed - in minutes - for a certain activity is the sum of the times needed to perform a certain subactivity, taken into account that certain request characteristics, like the fact whether the request concerns a book or journal article, influence the presence of certain terms in the equation. For that reason, these characteristics are included by dummy variables, which are equal zero or one, the latter when the request actually shows this characteristic and its time needs to be included in the time calculation. The role of these dummy variables needs to be emphasized, as these variables are crucial in understanding the utilization of the time equations. Furthermore, the time equations are set up chronologically, implying that both the main activities and the subactivities occur in the order of the position in their time equation. We will now discuss the different equations and indicate which subactivities correspond to the times in the equations.

\section{Outgoing Request}

An outgoing request starts with processing the request. This activity always requires library staff to receive the request either personally or electronically, to select a library possessing the requested book or article, to send the request to this library, to make a print-out, to enter data in an Excel-file, and finally to classify all print-outs $(6.8 \mathrm{~min})$. Besides these activities, the request potentially includes two extra activities, increasing the time needed to process the request. First, the reader may ask library staff feedback via e-mail, telephone, or at the library desk (6.3 $\mathrm{min}$ ). Second, the other supplying library may negatively respond, implying that the Arenberg library staff has to start over the process $(6.6 \mathrm{~min})$. Sometimes, in case of a rare document that is difficult to find, this process may need to be repeated several times. In that case, this term in the time equation has to be added more than once as well. Furthermore, we want to remark that the actual time equation does not take into account the experience of the different library employees working on ILL.

The second main activity of an outgoing request concerns the delivery and is substantially different for an article in PDF, 


\section{Table 1}

Time Equations Per Main ILL Activity

\begin{tabular}{|c|c|c|}
\hline Type of ILL Request & Main Activity & Total Time Needed Per Activity (In Minutes) ${ }^{\mathbf{a}}$ \\
\hline \multicolumn{3}{|l|}{ Outgoing request } \\
\hline & Process & $6.8+(6.3 *$ feedback $)+(6.6 *$ negative $)$ \\
\hline & Deliver & $\begin{array}{l}(3.2 * \text { article-in-PDF })+\left[\left(3+3^{\mathrm{b}}+(2.4 * \text { successful })+(1 * \text { unsuccessful })\right) * \text { article-on-paper }\right]+ \\
{[(6.3+(5 * \text { prolongation })) * \text { book }]}\end{array}$ \\
\hline & Close & $(0.7 *$ article $)+[(3.5+(2 *$ reminder $)) *$ book $]$ \\
\hline & Invoice & $\begin{array}{l}{\left[\left(0.8+0.2^{\mathrm{c}}\right) * \text { supplier-invoice }\right]+\left(0.5^{*} \text { IFLA }\right)+\left(3.5^{*} \text { no-client-invoice }\right)+} \\
{\left[\left(0.8+0.2^{\mathrm{d}}\right) * \text { client-invoice }\right]}\end{array}$ \\
\hline \multicolumn{3}{|l|}{ Incoming request } \\
\hline & Process & $3.2+(6.3 *$ feedback $)+(2 *$ negative $)+(4.4 *$ article-on-paper $)+(2.5 *$ book $)$ \\
\hline & Deliver & $\begin{array}{l}(2 * \text { article-in-PDF })+[(3.4+(2.4 * \text { successful })+((4+(2.4 * \text { second-successful })+ \\
(1 * \text { second-unsuccessful })) * \text { unsuccessful })) * \text { article-on-paper }]+[(5.1+(4 * \text { reservation })) * \text { book }]\end{array}$ \\
\hline & Close & $(0.7 *$ article $)+(2.2 *$ book $)$ \\
\hline & Invoice & {$\left[\left(0.8+0.2^{\mathrm{e}}\right) *\right.$ client-invoice $]+(0.5 *$ IFLA $)$} \\
\hline
\end{tabular}

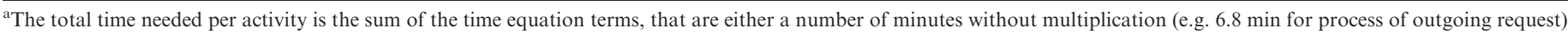

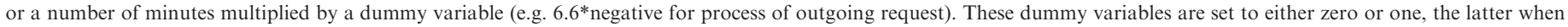
this specific request characteristic is present.

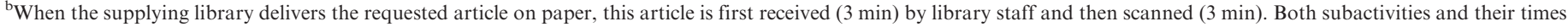
needed are separated in the time equation, because they are subject to a different cost per minute, as made clear in Table 2.

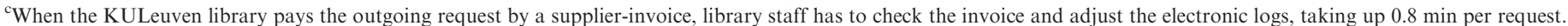
Then the accountant actually books the invoice $(0.2 \mathrm{~min})$. As the accountant is more expensive than other library staff, both subactivities are separated (cf. Table 2$)$.

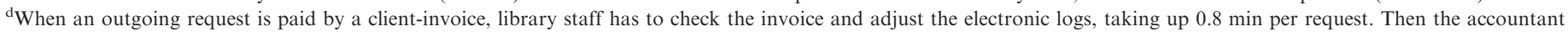
actually books the invoice $(0.2 \mathrm{~min})$. As the accountant is more expensive than other library staff, both subactivities are separated (cf. Table 2 ).

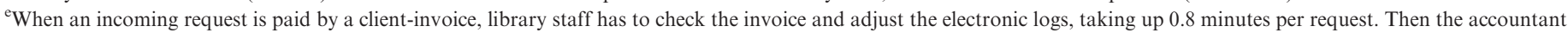
actually books the invoice ( 0.2 minutes). As the accountant is more expensive than other library staff, both subactivities are separated (cf. Table 2 ).

an article on paper or a book, as shown with dummy variables in the time equation for this activity. Journal articles are sent electronically when possible. Library staff then receives the article via e-mail, temporarily saves the article in the PDF database, and sends the paper to the reader via e-mail (3.2 min). However, when the article is received on paper via postal mail or shuttle service ( $3 \mathrm{~min})$, it is scanned into a PDF file ( $3 \mathrm{~min}$ ) and, if successful, temporarily saved and send via e-mail (2.4 $\min$ ). When the scan was unsuccessful, the original hardcopy of the article on paper is put in an envelope and sent via postal mail (1 min). Obviously, a book is always received physically through postal mail or shuttle service, after which the user is notified via e-mail and a copy of the request is stored $(6.3 \mathrm{~min})$. However, if the reader requests a prolongation on the book, library staff has to contact the supplying library, ask a loan period extension, and mail the answer to the reader, requiring an extra $5 \mathrm{~min}$.

After delivery, library staff closes the request in LIBIS and the Excel file, which takes $0.7 \mathrm{~min}$ for an article and $3.5 \mathrm{~min}$ for a book, because the latter also needs to be sent back to the owner library by postal mail or shuttle. When the book is not returned in time, a reminder is sent to the reader ( $2 \mathrm{~min}$ ).

Finally, invoicing is usually dealt with by the clearing house of the Impala system. In most other cases, the KULeuven library receives an invoice, which is checked, entered in the Excel file $(0.8 \mathrm{~min})$, and subsequently dealt with by the accountant $(0.2 \mathrm{~min})$. If the supplying foreign library is paid with an IFLA voucher, library staff only needs $0.5 \mathrm{~min}$ to perform the payment. The reader pays the ILL fee at the library desk in advance $(3.5 \mathrm{~min})$. Yet, if the reader is connected to a university department, a client-invoice is made based on the Excel-file data $(0.8 \mathrm{~min})$. These data are handed over to the accountant, who draws up the invoice and follows up on the payment $(0.2 \mathrm{~min})$.

\section{Incoming Request}

Similar to outgoing requests, incoming requests start with processing, which involves printing the request, entering data in an Excel-file, classifying the print-outs, and searching books and journal articles in the LIBIS-catalogue and e-sources subscriptions $(3.2 \mathrm{~min})$. If the Arenberg library does not possess the requested item, library staff negatively responds to the requesting library $(2 \mathrm{~min})$. Then, library staff searches the shelves, which takes up $2.5 \mathrm{~min}$ for a book and $4.4 \mathrm{~min}$ for a journal article, because journal volumes need to be checked. Obviously, the reader or requesting library may also ask feedback via e-mail, telephone or at the library desk (6.3 min).

Secondly, the requested article or book has to be delivered. A PDF file of a requested journal article is sent by e-mail to the requesting library (2 min). An article on paper is scanned, by one or more students working part-time at the library (3.4 min). If successful, library staff saves the PDF file and sends it via email $(2.4 \mathrm{~min})$. Otherwise, the article is copied, subsequently scanned (4 min), and delivered, meaning either a second successful PDF version via e-mail (2.4 min) or the hard copy via postal mail or shuttle service (1 min). A book is packed, 
made ready for transportation, and sent, after which its status is changed in the $\log$ file $(5.1 \mathrm{~min})$. If a reservation is made for a book that has been borrowed, library staff will process the reservation with a message sent in LIBIS (4 min).

Concerning closure, library staff will close an article request in LIBIS and the Excel file $(0.7 \mathrm{~min})$. After a lend book is received back, this request will also be closed in both LIBIS and the Excel file (2.2 $\mathrm{min})$.

Because invoicing between the Arenberg library and other Belgian libraries is almost always done via the Impala system, only a minority of incoming requests lead to an invoice, handled by the same workflow as the client-invoice of an outgoing request made for the requesting department $(0.8 \mathrm{~min}$ from library staff and $0.2 \mathrm{~min}$ from the accountant). Yet, if a requesting foreign library pays with an IFLA voucher, library staff only needs 0.5 min to handle the payment.

\section{Identification of the Cost Per Minute}

In this part of the TDABC analysis, we identify how much one time unit - $1 \mathrm{~min}$ - of every activity, defined in the previous step, actually costs. All cost rates were calculated by means of data provided by the library manager. According to him, the total number of personnel assigned to ILL represents 2.5 full time equivalents. With a theoretical capacity of $38 \mathrm{~h}$ a week, a total of $95 \mathrm{~h}$ would be available for ILL activities per week. Yet, instead of using this utopian kind of capacity, we base our calculations on the more realistic practical capacity, which is set at 80 percent of the theoretical capacity, a standard number in the management accounting literature (e.g. Kaplan and Anderson ${ }^{6}$ ) and also the number given by the ILL responsible. Therefore, the practical capacity for ILL activities is $76 \mathrm{~h}$ or $4560 \mathrm{~min}$ per week.

\section{"In... [time-driven activity based costing] analysis, we identify how much one time unit - one minute - of every activity, defined in the previous step, actually costs."}

The 2.5 FTE consist of six people, each working 100 percent (the ILL responsible), 75 percent, 37.5 percent, 25 percent, 6.25 percent, and 6.25 percent of their time on ILL. Based on their different gross wages, the total labor cost of these people is $€ 1,521.56$ per week. Dividing this amount by the practical capacity of 4560 min per week, results in a cost of $€ 0.33$ per minute. Besides these employees, the Arenberg library hires students to perform scanning and copying activities for incoming requests. Based on their hourly wage, we calculated their labor cost per minute as $€ 0.28$. Finally, the Arenberg library also employs an accountant, who books invoices to readers and deals with the potential payments of supplying and requesting libraries. His monthly gross wage is $€ 3,117.11$, implying that his cost per minute amounts to $€ 0.43$.

According to the Arenberg library accountant, the ILL overhead costs concern equipment and daily working costs. In the same way, so by dividing total costs by total number of minutes (4560 per week), we calculated a general overhead cost of $€ 0.03$ per minute, covering furniture, computers, computer supplies, and paper. In addition, article requests can require copying and scanning activities for which a specific cost of $€ 0.02$ per minute is derived, covering the scanner/copier and all related costs, such as paper and maintenance. Finally, we also distinguish a specific shipping cost of $€ 0.02$ per minute.

Based on these separate cost rates, we identify five activity cost rates. The first cost rate is the fully loaded staff labor cost of $€ 0.36$ per minute, including labor costs and general overhead costs. In case the ILL request involves sending a book or article on hard copy, we add a specific shipping cost of $€ 0.02$ per minute. Third, the fully loaded student labor cost rate equals $€ 0.31$ per minute, covering labor cost $(€ 0.28)$ and overhead (€0.03). Next, the accountant costs $€ 0.46$ per minute, based on his labor cost $(€ 0.43)$ and the overhead cost $(€ 0.03)$. Finally, the machine cost rate for scanning and copying equals $€ 0.02$ per minute. These five cost rates will be used to calculate the different costs for different requests in the following paragraph and are summarized in Table 2.

\section{Cost Calculation of Inter-Library Loans}

In this part, we derive two cost tables to calculate the cost of a specific ILL request, one for outgoing and one for incoming requests. Yet in order to facilitate the cost calculation, we explicate a second distinction, namely the one between journal articles and books. Obviously, this distinction was already implicitly present in the time equations, by means of dummy variables. However, as our cost tables do not contain dummy variables, this distinction is needed to add all appropriate costs. Furthermore, we also distinguish between articles on paper and articles in PDF, in order to increase the clarity of our cost tables.

Table 3 shows the cost table for the three types of outgoing requests.

This table can be used to calculate both the total time needed to handle the request and the cost of all activities related to the request. To this end, one first identifies whether the outgoing request deals with a book, article available in PDF, or article available on paper. When the appropriate main column is selected, the rows of this type of outgoing request must be read from top to bottom. Every row in the table represents one activity and contains the activity description, time needed (in minutes), and cost incurred (in $€$ ). The activity description in the first column and time in the second column result from the different time equations in step one of the analysis. The third column indicates the cost of performing an activity once and results from multiplying the time needed by the cost per minute for that activity, identified in step two of the analysis (cf. Table 2). Obviously, we are mainly interested in these costs in order to calculate the total cost. Yet, the column with the number of minutes per activity is included in the cost table to allow pellucid calculation of the total handling time needed. Ulti-

Table 2

Costs Per Minute

\begin{tabular}{lc}
\hline \multicolumn{1}{c}{ Cost Type } & Cost Per Minute \\
\hline Staff labor cost & 0.36 \\
Staff labor cost + shipping cost & 0.38 \\
Student labor cost & 0.31 \\
Accountant labor cost & 0.46 \\
Scanning machine cost & 0.02 \\
\hline
\end{tabular}


Table 3

Outgoing Request Cost Table

\begin{tabular}{|c|c|c|c|c|c|c|c|c|c|}
\hline & \multicolumn{9}{|c|}{ Outgoing Request ${ }^{i}$} \\
\hline & \multicolumn{3}{|c|}{ Book } & \multicolumn{3}{|c|}{ Article in PDF } & \multicolumn{3}{|c|}{ Article on Paper } \\
\hline & Activity & Time & Cost & Activity & Time & Cost & Activity & Time & Cost \\
\hline \multirow{11}{*}{ 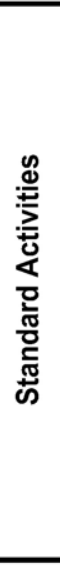 } & Process & 6.8 & 2.45 & Process & 6.8 & 2.45 & Process & 6.8 & 2.45 \\
\hline & Deliver & 6.3 & 2.27 & Save + Send & 3.2 & 1.15 & Receive & 3 & 1.08 \\
\hline & & & & & & & Scan & 3 & 1.14 \\
\hline & & & & & & & Save + Send & 2.4 & 0.86 \\
\hline & & & & & & & or if scan unsuccessful & or & or \\
\hline & & & & & & & Send hardcopy & 1 & 0.38 \\
\hline & Close & 3.5 & 1.26 & Close & 0.7 & 0.25 & Close & 0.7 & 0.25 \\
\hline & & 0.8 & 0.29 & & 0.8 & 0.29 & & 0.8 & 0.29 \\
\hline & Client-invoice & 0.2 & 0.09 & Client-invoice & 0.2 & 0.09 & Client-invoice & 0.2 & 0.09 \\
\hline & or & or & or & or & or & or & or & or & or \\
\hline & No-client-invoice & 3.5 & 1.26 & No-client- invoice & 3.5 & 1.26 & No- client-invoice & 3.5 & 1.26 \\
\hline & Subtotal" & $\cdots$ & $\cdots$ & Subtotal & $\cdots$ & $\cdots$ & Subtotal ${ }^{\text {II' }}$ & $\cdots$ & $\cdots$ \\
\hline \multirow{7}{*}{ 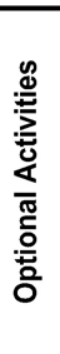 } & $\overline{\text { Negative }}$ & 6.6 & 2.38 & Negative & 6.6 & 2.38 & Negative & 6.6 & 2.38 \\
\hline & Feedback & 6.3 & 2.27 & Feedback & 6.3 & 2.27 & Feedback & 6.3 & 2.27 \\
\hline & Supplier-invoice & 0.8 & 0.29 & | Supplier-invoice & 0.8 & 0.29 & Supplier-invoice & 0.8 & 0.29 \\
\hline & & 0.2 & 0.09 & & 0.2 & 0.09 & 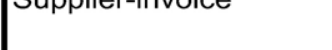 & 0.2 & 0.09 \\
\hline & IFLA & 0.5 & 0.18 & IFLA & 0.5 & 0.18 & IFLA & 0.5 & 0.18 \\
\hline & Reminder & 2 & 0.72 & & & & & & \\
\hline & Prolongation & 5 & 1.80 & & & & & & \\
\hline & Subtotal $^{i v}$ & $\cdots$ & $\cdots$ & Subtotal & $\cdots$ & $\cdots$ & Subtotal & $\cdots$ & $\cdots$ \\
\hline
\end{tabular}

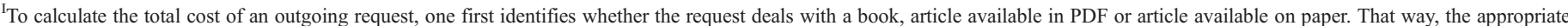

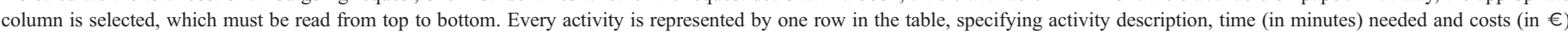
incurred. The total cost of an outgoing request is the sum of the two subtotals. The calculation of the total time needed is similar to the cost calculation.

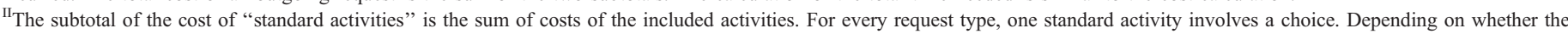

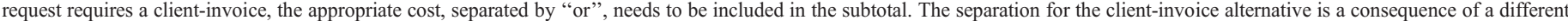
cost per minute $(0.36 €$ and $0.43 €)$ for the two related subactivities (cf. Tables 1 and 2 ).

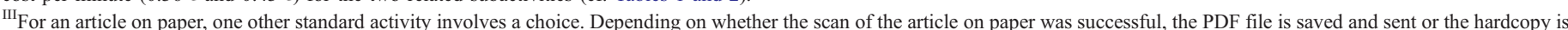

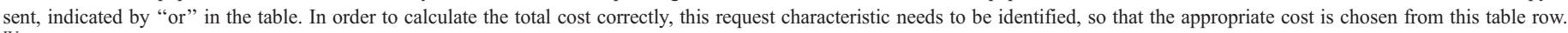

${ }^{\mathrm{IV}}$ The subtotal of optional activities is also the sum of the included activities, taking into account that all costs are added only when the characteristic is present.

mately, the total cost of an outgoing request is the sum of two subtotals, visualized by two sections at the left hand side of the table.

The first subtotal of "standard activities" is the sum of the costs of the activities in this section of the table. For each of the three request types, one of these standard activities involves a characteristic identification. Depending on whether the request requires a client-invoice or not, the appropriate cost, separated by "or" in the table, needs to be included in the subtotal. For an article on paper, another identification has to be made. Depending on whether the scan of the article on paper was successful, the PDF file is saved and sent or the hardcopy is sent, indicated by "or" in the table. In order to calculate the total cost correctly, these request characteristics need to be identified in beforehand, so that the appropriate costs are chosen from the table. The subtotal of "optional activities" is also the sum of the included activities in this table section, taking into account that all costs are added only when the characteristic is identified to be present.

So to calculate the total cost of a certain outgoing request, we first need to identify the type of request - book, article in PDF, or article on paper - and the characteristics determining the occurrence of certain activities. Then, we sum the costs of the identified activities into two subtotals. Finally, these subtotals are added into the total cost. Let us explain this approach by a thorough example.

Assume that the KULeuven library receives the request from a reader to order a certain journal article via ILL. The reader did not find the journal article in the library collection and asks for help at the library desk. After he hears about the possibility of ILL, he fills in a request form and says he prefers an invoice to payment in cash. Yet, the journal article appears difficult to find, as the first supplying library negatively responds to the ILL request. In addition, the 
second supplying library sends the article on paper, so that a scan is performed. Yet, this scan appears unsuccessful, so that the hardcopy of the article is sent by postal mail. Finally, the foreign supplying library requests payment by means of an invoice.

In order to calculate the total cost of this request, we first need to identify its type and characteristics. It is clear that this request concerns an outgoing request of an article that is delivered on paper by the supplying library. That means that we consider the third main column of Table 3 and need to include the standard activities of processing $(€ 2.45)$, receiving $(€ 1.08)$, and scanning $(€ 1.14)$ in the addition of the first subtotal. Furthermore, we know that the article is scanned unsuccessfully, so that the hardcopy is sent to the reader by postal mail $(€ 0.38)$. Hence, we select this activity of the fourth row. After closing ( $€ 0.25)$, this request is paid via an invoice $(€ 0.29+€ 0.09)$. Therefore, the subtotal of standard activities amounts to $€ 5.68$. Additionally, this request is hampered by a first negative request $(€ 2.38)$ and requires feedback ( $€ 2.27)$, as well as a supplier-invoice, since the payment is not handled by Impala $(€ 0.29+€ 0.09)$. This leads to a second subtotal of $€ 5.03$ for optional activities. Hence, the total cost to handle this outgoing request amounts to $€ 10.71$. In the same way, the subtotal of time needed for standard activities adds up to $15.5 \mathrm{~min}$. As the optional activities require $13.9 \mathrm{~min}$, the total time needed to handle this outgoing request is $29.4 \mathrm{~min}$.

The cost table for incoming requests, shown as Table 4, is very similar to the one for outgoing requests and can be used accordingly.

\section{Incoming Request Cost Table}

\begin{tabular}{|c|c|c|c|c|c|c|c|c|c|}
\hline & \multicolumn{9}{|c|}{ Incoming Request ${ }^{x}$} \\
\hline & \multicolumn{3}{|c|}{ Book } & \multicolumn{3}{|c|}{ Article in PDF } & \multicolumn{3}{|c|}{ Article on Paper } \\
\hline & Activity & Time & Cost & Activity & Time & Cost & Activity & Time & Cost \\
\hline \multirow{3}{*}{ 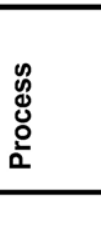 } & Process & 3.2 & 1.15 & Process & 3.2 & 1.15 & Process & 3.2 & 1.15 \\
\hline & Negative & 2 & 0.72 & Negative & 2 & 0.72 & Negative & 2 & 0.72 \\
\hline & Subtotal ${ }^{\mathrm{xT}}$ & $\ldots$ & $\ldots$ & Subtotal & $\ldots$ & $\ldots$ & Subtotal & $\ldots$ & $\ldots$ \\
\hline \multirow{9}{*}{ 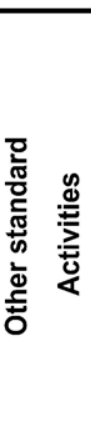 } & Search & 2.5 & 0.90 & Save + Send & 2 & 0.72 & Search & 4.4 & 1.58 \\
\hline & Deliver & 5.1 & 1.94 & & & & Scan & 3.4 & 1.12 \\
\hline & & & & & & & Save + Send & 2.4 & 0.86 \\
\hline & & & & & & & or if scan unsuccessful & or & or \\
\hline & & & & & & & Copy $+2^{\text {nd }}$ scan of copy & 4 & 1.32 \\
\hline & & & & & & & Save + Send & 2.4 & 0.86 \\
\hline & & & & & & & Or if $2^{\text {nd }}$ scan unsuccessful & or & or \\
\hline & & & & & & & Send hardcopy & 1 & 0.38 \\
\hline & Close & 2.2 & 0.79 & Close & 0.7 & 0.25 & Close & 0.7 & 0.25 \\
\hline & Subtotal ${ }^{\mathrm{xiI}}$ & $\ldots$ & $\ldots$ & Subtotal & $\ldots$ & $\ldots$ & Subtotal ${ }^{\mathrm{xiII}}$ & $\ldots$ & $\ldots$ \\
\hline \multirow{5}{*}{ 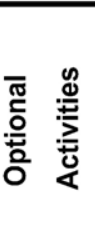 } & Feedback & 6.3 & 2.27 & Feedback & 6.3 & 2.27 & Feedback & 6.3 & 2.27 \\
\hline & Clirentingin & 0.8 & 0.29 & Cliontinugin & 0.8 & 0.29 & Cliontingine & 0.8 & 0.29 \\
\hline & - & 0.2 & 0.09 & & 0.2 & 0.09 & 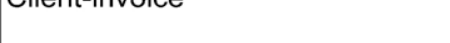 & 0.2 & 0.09 \\
\hline & IFLA & 0.5 & 0.18 & IFLA & 0.5 & 0.18 & IFLA & 0.5 & 0.18 \\
\hline & Reservation & 4 & 1.44 & & & & & & \\
\hline & Subtotal $\left.\right|^{x / v}$ & $\ldots$ & $\ldots$ & Subtotal & $\ldots$ & $\ldots$ & Subtotal & $\ldots$ & $\ldots$ \\
\hline
\end{tabular}

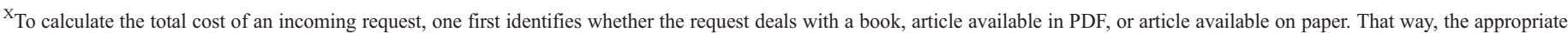

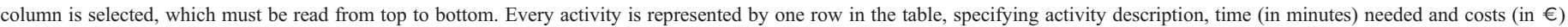
incurred. The total cost of an incoming request is the sum of the three subtotals. The calculation of the total time needed is similar to the cost calculation.

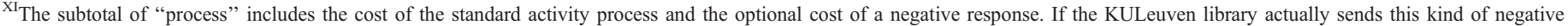
response, no other activities than process occur, implying that this subtotal becomes the total cost.

XIThe subtotal of "other standard activities" is the sum of the costs of the included activities.

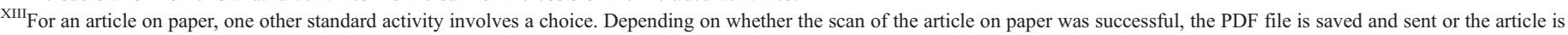

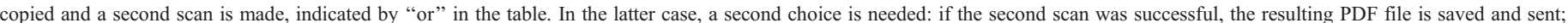

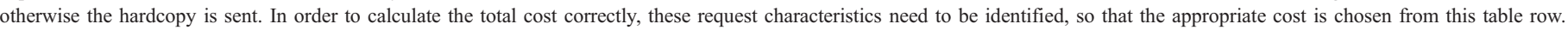
XIV The subtotal of "optional activities" is also the sum of the included activities, taking into account that all costs are added only when the characteristic is present.
} 
Two differences with the outgoing request cost table worth mentioning are the following. First, this cost table includes an extra subtotal, named process, which separates the standard activity of process from the other standard activities (the second subtotal). The reason for this approach is the possibility that the KULeuven library sends a negative response to the requesting library. In that case, no other standard activities than process occur for this request, implying that this subtotal becomes $5.2 \mathrm{~min}$ or $€ 1.87$. Obviously, this cost, potentially supplemented by a cost of $€ 2.27$ for providing feedback, is a complete loss for the KULeuven library, as it does not receive a fee for delivering a negative response. Yet, if the library does find the requested book or journal article in its collection, negative is not selected. Therefore, this subtotal amounts to $€ 1.15$, which has to be added to the resulting subtotal of other standard and optional activities. Second, an article on paper involves a second choice in the other standard activities subtotal. As in the case of an outgoing request, the requested article found on paper is scanned, so that it can be sent electronically. Hence, the first choice in the cost calculation is the same, namely whether the scan is successful. Yet, if the scan appears unsuccessful, the article is not immediately sent on hardcopy, but copied so that a second scan can be made of the copied version. If this second scan is successful, the resulting PDF file is saved and sent; otherwise the hardcopy is sent. Hence, in the incoming case a second choice is needed, namely whether the second scan is successful, which implies the addition of more time and cost and is indicated by "or" in the table.

\section{The Benefits of TDABC: Some Management IMPLICATIONS}

In order to adequately assess the ILL costs of the Arenberg library, we need to compare those costs with the ILL "earnings", the price which the library charges to the reader or requesting library. This price is fixed at $€ 8$. Although this price covers the costs of simple requests, this amount will not cover more complicated requests with several options, like the outgoing article on paper request $(€ 10.71)$, described in the previous paragraph. Outgoing request characteristics like feedback, potential negative response from the supplying library, payment in cash, reminder, and prolongation in case of a book and scanning in case of an article on paper, all significantly increase the cost of this type of request. Some characteristics are less prevalent for incoming requests, although feedback, reservation, and especially scanning remain resource consuming characteristics.

Therefore, we can conclude that ILL earnings often do not cover ILL costs. The TDABC approach, with its time equations, offers some specific advantages, as these equations create larger transparency than a traditional cost accounting system or an ordinary ABC system. The time equations clearly show which activities demand more time, and thus lead to higher costs. This way, the library manager can take appropriate actions to lower the time needed to handle a certain request.

First, the time equations show that scanning and copying an article on paper consume a relatively large amount of time. This activity requires $3 \mathrm{~min}$ for an outgoing request, while an incoming request demands a scanning time between 3.4 and 7.4 min. Discussions with the library manager revealed that scanning articles is a time consuming activity, because the scanner is outdated. Hence, we argue that it is worthwhile to investigate the possibility of buying a more professional scanner. This kind of scanner would not only lower the scanning time, but also augment the quality of the first scan, thereby reducing the possibility to need a second scan. One could, of course, also consider abandoning the approach of scanning articles on paper, as this activity consumes relatively much time and appears unsuccessful in more than half of the requests. Yet, this recommendation was considered incompatible with the fundamental mission of the Arenberg library, which is to offer the best possible service. Concerning ILL, this service implies that the library wants to deliver the requested articles as soon as possible. As an article in PDF can be sent by e-mail instead of postal mail, the mission enforces scanning articles. Furthermore, the library manager indicated that readers benefit from getting an electronic version instead of a hard copy, as the first is more easily stored and retrieved. Finally, the PDF files also offer the possibility to be re-used by the Arenberg library. After the article is successfully scanned, the PDF file is stored in the PDF database, so that it can be copypasted for future requests of the same article.

Second, we notice that the search activity requires approximately 75 percent of the process time, depending on the specific characteristics of the request. In addition, we wonder whether the Arenberg library staff actually adds any value with this activity, meaning: is the reader not able to perform this search his- or herself? If so, the library manager can consider outsourcing this activity to the reader, by improving and simplifying the search process via the Internet. Hence, the search costs identified in our analysis form the base against which the related process change costs need to be compared.

Third, the library should consider improving the activity of providing feedback, as this potential request characteristic takes up $€ 2.27$ of the $€ 8$ ILL fee. A possible process improvement would be to set up an electronic portal with a "Frequently Asked Questions" section and the possibility to post other questions. This way, readers could find the answers to previously asked questions, which are already in the database, themselves. At the same time, library staff could easily add answers to new questions, still being raised via the portal. The cost of this portal needs to be weighted against the cost of providing feedback individually.

\section{"TDABC [Time-driven activity based costing analysis] offers the possibility to visualize which activities consume the largest amount of time and are thus most suitable for amelioration, in order to reduce the total ILL service cost."}

The main point of this discussion is the fact that these suggestions for improvement show the strength of the analysis, as they are all based on the time equations and subsequent cost calculations. TDABC offers the possibility to visualize which activities consume the largest amount of time and are thus most suitable for amelioration, in order to reduce the total ILL service cost.

Although the previous paragraph exclusively deals with costs, there exists a second way to improve the balance 
between ILL costs and earnings, namely altering the price for ILL. Based on the time equations, it becomes clear that when library staff tries to speed up the delivery, it increases the cost as well; think for example of the scanning activity in the case of an article on paper. Yet, one can imagine that some readers value this service more than others, and thus are prepared to pay extra for it. Based on the cost calculation, the library manager can introduce a price differentiation between high service and low service ILL, with the first being more expensive than the latter. However, the library manager argued that the library mission (again) opposes such a price strategy. The Arenberg library wants to offer the best possible service to everyone and not only to those able and/or willing to pay for it. Nevertheless, there is one category of "customers" that does qualify for price differentiation, namely companies requesting books or journal articles. Indeed, several large pharmaceutical and technology companies are frequent ILL users. Based on the TDABC information of our analysis, the library manager could discuss the current service level and easily argue that he needs to either raise the ILL price or lower the ILL service, in order to cover the ILL expenses. Our time equations and cost calculations support such a discussion with the necessary relevant evidence, and form a benefit confirmed by the library manager. Finally, the library manager could consider a similar discussion with the university management in order to request and justify an increase in library funding.

\section{Conclusion}

In this paper, we have set up a time-driven activity-based costing (TDABC) system for the inter-library loan (ILL) service of the KULeuven Arenberg library. Based on cost tables III and IV, borrowing costs appear to range from $€ 4.23$ (for the simplest article delivery) to $€ 14.79$ (for the most complex book loan), while incoming request costs range from $€ 2.12$ (for the simplest article delivery) to $€ 8.93$ (for the most complex article delivery). These results are comparable with the cost rates found by the most recent ILL cost study of the Association of Research Libraries: ${ }^{14,15}$ borrowing unit costs for user-initiated ILL ranging from $\$ 2.39$ to $\$ 14.7$ and userinitiated lending unit costs ranging from \$3.27 to \$12.06. Yet, they are slightly smaller than average costs ( $€ 12.56$ for borrowing and $€ 7.24$ for lending) found in the Nordic ${ }^{13}$ and significantly lower than the total average per unit cost of \$41.20, found at the NIST Library. ${ }^{19}$ At the same time, however, the KULeuven library's ILL costs appear several times bigger than the circulation cost around 1 dollar at OhioLINK ${ }^{17}$ or Prospector. ${ }^{18}$ Nevertheless, the most significant benefit of our TDABC analysis lies in the ability to disaggregate per-transaction costs, based on a thorough activity analysis that in the end visualizes the true cost of different activities for different ILL requests. That way, the analysis also (and perhaps most importantly) allows managerial recommendations concerning amelioration opportunities. For example, since TDABC makes it possible to distinguish the scanning of PDF files as a resource intensive activity, the library manager can use this information to consider the investment in a professional scanner. Furthermore, the TDABC analysis shows that "searching" and "providing feedback" consume a large amount of resources. Based on these findings, potential ameliorations can be investigated, such as outsourcing the search activity to the user and improving the feedback process by means of a FAQ portal. Hence, our case study not only shows how the time-driven cost accounting technique works in practice, by means of clear time equations, cost tables, and several recommendations, but also exemplifies the additional benefit of disaggregated time-driven activity-based costs compared to traditional ILL cost studies. Therefore, we argue that this cost accounting technique is very suited to cope with the increasing cost pressures that university libraries currently experience, in particular related to ILL services.

Hence, this paper bridges the library and cost accounting literatures. First and most importantly, our study contributes to the library literature by offering an innovative technique to either reduce ILL resource costs or renegotiate ILL service prices. Based on the case study evidence of the Arenberg library, we conclude that TDABC can contribute to the provision of better library services at lower costs. Yet, our paper also contributes to the cost accounting literature by testing the usefulness of a new revised $\mathrm{ABC}$ technique in practice. In that respect, our study is one of the first to offer clear evidence that TDABC does accomplish the postulated benefits, when performed in practice.

Finally, we want to emphasize some interesting future research opportunities on this topic. Obviously, the results of our case study would be more informative when compared to a reference. Therefore, it would be interesting to perform a similar case study of TDABC for ILL in another (university) library. Based on the resulting data, a benchmark study could offer interesting additional information to lower the costs or to increase the quality of the ILL service. Moreover, it looks very promising to apply the TDABC approach to other library services. In that respect, the Arenberg library manager suggested performing a TDABC analysis on the activity "acquisition", which has similar characteristics (complex, time consuming and lots of variation) suggesting a high TDABC usefulness.

Acknowledgments: We wish to thank the KULeuven Arenberg library staff, and especially Ludo Holans (library manager) and Monique Kumps (ILL responsible) for their cooperation and contribution to this paper. In addition, we gratefully acknowledge the assistance of Wannes Balieu and Silvie De Roose in collecting the data. Finally, we also thank an anonymous reader for helpful comments that improved the paper. Financial support by the Fund for Scientific Research, Flanders is gratefully acknowledged.

\section{Notes AND REFERENCES}

1. Paul Cropper \& Roger Cook, "Activity-Based Costing in Universities-Five Years On," Public Money and Management 20 (April-June 2000): 61-68.

2. Jennifer Ellis-Newman \& Peter Robinson, "The Cost of Library Services: Activity-Based Costing in an Australian Academic Library," The Journal of Academic Librarianship 24 (September 1998): $373-379$.

3. Jennifer Ellis-Newman, "Activity-Based Costing in User Services of an Academic Library," Library Trends 51 (Winter 2003): $333-348$.

4. Maurice Pendlebury \& Nabih Algaber, "Accounting for the Cost of Central Support Services in UK Universities: A Note," Financial Accountability and Management 13 (August 1997): $281-288$.

5. Andrew Goddard \& Kean Ooi, "Activity-Based Costing and Central Overhead Cost Allocation in Universities: A Case Study," Public Money and Management 18 (July-September 1998): $31-38$ 
6. Robert S. Kaplan \& Steven R. Anderson, "Time-Driven ActivityBased Costing," Harvard Business Review 82 (November 2004): $131-138$.

7. Danuta A. Nitecki \& Patricia E. Renfro, "Borrow Direct: A Case Study of Patron-Initiated Interlibrary Borrowing Service," The Journal of Academic Librarianship 30 (March 2004): 132-135.

8. Julia C. Blixrud, Assessing Library Performance: New Measures, Methods, and Models. Online. Association of Research Libraries. Available: http://www.iatul.org/conference/proceedings/vol13/ papers/BLIXRUD_fulltext.pdf (2003).

9. Joan E. Stein, "Measuring the Performance of ILL and Document Supply: 1986 to 1998," Performance Management and Metrics 2/ 1 (2001): 11-72.

10. Marilyn M. Roche, ARL/RLG Interlibrary Loan Cost Study, edited by (Washington, DC: Association of Research Libraries, 1993) p. 73.

11. Mary E. Jackson, "Measuring the Performance of Interlibrary Loan and Document Delivery Services," ARL: A Bimonthly Newsletter of Research Library Issues and Actions 195 (December 1997): 1-3.

12. Tom Ruthven \& Susan Magnay, "Top Performing Interlending Operations: Results of the Australian Benchmarking Study," Interlending and Document Supply 30/2 (2002): 73-79.
13. Pentti Vattulainen, Performance of Interlending in Nordic Academic Libraries. Online. NORDINFO Board. Available: http://inet.dpb.dpu.dk/nvbf/perform.pdf (August 22, 2003).

14. Mary E. Jackson, “Assessing ILL/DD Services Study: Initial Observations," ARL Bimonthly Report 230/231 (October/December 2003): 21-22.

15. Mary E. Jackson, “Assessing ILL/DD Services: New Cost-Effective Alternatives," ARL Bimonthly Report 236 (October 2004): 9.

16. David F. Kohl, "How the Virtual Library Transforms Interlibrary Loans-The OhioLINK Experience," Interlending and Document Supply 26/2 (1998): 65-69.

17. David F. Kohl \& Tom Sanville, "More Bang for the Buck: Increasing the Effectiveness of Library Expenditures Through Cooperation," Library Trends 54 (Winter 2006): 394-410.

18. Franca Rosen \& Leanne Emm, "The Cost of Getting What Patrons Want: A Study in Colorado Resource Sharing," Colorado Libraries 29/3 (2003): 35-38.

19. Rosa Liu \& Briget Wynne, "Analysis of Interlibrary Loan at the National Institute of Standards and Technology Library: Lessons Learned," Interlending and Document Supply 34/3 (2006): 115-118.

20. Peter J. Lor, "Measurement of Suppliers' Costs in a Large Decentralized Interlending System," South African Journal of Library and Information Science 60/3 (1992): 7-14. 